Elsevier required licence: (C) <2017>. This manuscript version is made available under the CC-BY-NC-ND 4.0 license http://creativecommons.org/licenses/by-nc-nd/4.0/ 


\section{Biomimetic aquaporin membranes for osmotic membrane bioreactors: Membrane performance and contaminant removal}

Revised manuscript submitted to Bioresource Technology September 2017

Wenhai Luo ${ }^{\text {a,c* }}$, Ming Xie ${ }^{\text {b }}$, Xiaoye Song ${ }^{c}$, Wenshan Guo ${ }^{\text {d }}$, Hao H. Ngo ${ }^{\text {d, Junliang Zhou }}{ }^{\text {d, }}$ Long D. Nghiem ${ }^{c}$

${ }^{a}$ Beijing Key Laboratory of Farmland Soil Pollution Prevention and Remediation, College of Resources and Environmental Sciences, China Agricultural University, Beijing, 100193, China

${ }^{b}$ Institute for Sustainability and Innovation, College of Engineering and Science, Victoria University, Melbourne, VIC 8001, Australia

${ }^{c}$ Strategic Water Infrastructure Laboratory, School of Civil, Mining and Environmental Engineering, University of Wollongong, Wollongong, NSW 2522, Australia

${ }^{d}$ Centre for Technology in Water and Wastewater, School of Civil and Environmental Engineering, University of Technology Sydney, Sydney, NSW 2007, Australia

\footnotetext{
*Corresponding author: luowenhai@cau.edu.cn; Ph: +86 18311430503.
} 


\section{Abstract}

In this study, we investigated the performance of an osmotic membrane bioreactor (OMBR) enabled by a novel biomimetic aquaporin forward osmosis (FO) membrane. Membrane performance and removal of 30 trace organic contaminants (TrOCs) were examined. Results show that the aquaporin FO membrane had better transport properties in comparison with conventional cellulose triacetate and polyamide thin-film composite FO membranes. In particular, the aquaporin FO membrane exhibited much lower salt permeability and thus smaller reverse salt flux, resulting in a less severe salinity build-up in the bioreactor during OMBR operation. During OMBR operation, the aquaporin FO membrane well complemented biological treatment for stable and excellent contaminant removal. All 30 TrOCs selected here were removed by over $85 \%$ regardless of their diverse properties. Such high and stable contaminant removal over OMBR operation also indicates the stability and compatibility of the aquaporin FO membrane in combination with activated sludge treatment.

Keywords: Aquaporin membrane; forward osmosis; osmotic membrane bioreactor; trace organic contaminant; activated sludge treatment

\section{Introduction}

Membrane bioreactors (MBRs), which integrate physical membrane separation process, such as microfiltration (MF) and ultrafiltration (UF), with conventional activated sludge (CAS) treatment, have been widely deployed for wastewater treatment and reuse. Compared to CAS treatment, MBRs have several advantages, including better effluent quality, lower sludge production, smaller footprint, and easier operation and maintenance (Huang \& Lee, 2015). For wastewater reuse that requires high water quality, further treatment, for example, by nanofiltration, reverse osmosis (RO), and advanced oxidation, is still necessary (Elimelech, 2006; Shannon et al., 
2008; van Loosdrecht \& Brdjanovic, 2014).

Forward osmosis (FO), an osmosis-driven process, was proposed recently to integrate with CAS to form a novel MBR, namely, osmotic MBR or OMBR (Achilli et al., 2009; Cornelissen et al., 2011; Holloway et al., 2015; Aftab et al., 2017). During OMBR operation, treated water from the bioreactor permeates through a semi-permeable FO membrane into a draw solution using osmotic pressure difference across the membrane as the driving force. A draw solution regeneration process, such as RO or membrane distillation (MD), can then be used to re-concentrate the draw solution and produce clean water for reuse applications (Holloway et al., 2014; Nguyen et al., 2016). By utilizing the osmotic pressure-driven process, OMBR can be a low fouling alternative to conventional MBR, in which hydraulically driven MF or UF membranes are commonly equipped (Achilli et al., 2009). Moreover, it has been demonstrated that membrane fouling of the RO process after OMBR is significantly less than that after conventional MBR (Luo et al., 2017). Unlike MF and UF membranes used in conventional MBR, FO membranes have a high rejection capacity for most contaminants, including trace organic contaminants ( $\mathrm{TrOCs}$ ) that remain vexing challenges to water reuse applications (Alturki et al., 2012; Holloway et al., 2014). Thus, OMBR can produce higher quality effluent in comparison to conventional MBR (Luo et al., 2017).

One critical issue in OMBR operation is salinity build-up in the bioreactor, which could alter sludge characteristics, inhibit biological activity, and thus deteriorate OMBR performance (Luo et al., 2017). Such unfavorable salinity build-up was driven by the high salt rejection by the FO membrane, and more importantly, the reverse draw solute permeation into the bioreactor. Despite the advancement in FO membranes from cellulose triacetate (CTA) to polyamide thin-film composite (TFC) (Fane et al., 2015; Werber et al., 2016), salinity build-up remains hindrance to the further development and deployment of OMBR. Thus, recent efforts have been dedicated to control salinity build-up during OMBR operation by periodically 
discharging mixed liquor (Wang et al., 2014a), integrating with porous membranes for salt bleeding (Wang et al., 2014b; Holloway et al., 2015), and employing biodegradable draw solutes (Bowden et al., 2012; Luo et al., 2016a). However, these strategies cannot completely address the issue of salinity build-up in OMBR. Indeed, the development of novel FO membranes with low salt permeability is the most effective to control salinity build-up (Fane et al., 2015).

Biomimetic membranes, based on aquaporins, have the potential to further advance FO and OMBR processes (Tang et al., 2015; Li et al., 2016; Giwa et al., 2017). Aquaporins are water-channel proteins in biological cell membrane. Each aquaporin channel is capable of transporting up to $10^{9}$ water molecules per second and absolute rejection of all other solutes (Jensen \& Mouritsen, 2006). Madsen et al. (2015) reported that the aquaporin FO membrane exhibited nearly 97\% rejection of three neutral TrOCs, namely atrazine, 2,6-dichlorobenzamide and desethyl-desisopropyl-atrazine. By introducing aquaporins into polymeric membranes, the permeability-selectivity trade-off of conventional TFC membranes could be considerably overcome ( $\mathrm{Li}$ et al., 2015). Li et al. (2017) reported that incorporating aquaporin proteins into the polyamide selective layer of a hollow fiber TFC FO membrane could largely increase the membrane water flux while reduce the reverse salt flux. Nevertheless, there is a dearth in current literature on the performance of biomimetic FO membranes in OMBR operation, where the biocompatibility of these newly developed membranes is challenged.

In this study, the performance of an aquaporin-based biomimetic FO membrane in OMBR operation was investigated. Key properties of the aquaporin membrane were characterized and compared to conventional CTA and TFC FO membranes. The aquaporin membrane performance in OMBR operation was evaluated in terms of water flux, bioreactor salinity, and contaminant removal. Role of the aquaporin FO membrane in OMBR for TrOC removal was also quantified. Results from this study provide important implications to examine the compatibility and potential of 
biomimetic aquaporin membranes for OMBR applications.

\section{Materials and methods}

\subsection{Synthetic wastewater and trace organic contaminants}

A synthetic wastewater was used as the OMBR influent. This synthetic wastewater was prepared daily and consisted of $100 \mathrm{mg} / \mathrm{L}$ glucose, $100 \mathrm{mg} / \mathrm{L}$ peptone, $17.5 \mathrm{mg} / \mathrm{L}$ $\mathrm{KH}_{2} \mathrm{PO}_{4}, 17.5 \mathrm{mg} / \mathrm{L} \mathrm{MgSO}_{4}, 17.5 \mathrm{mg} / \mathrm{L} \mathrm{CaCl}_{2}, 10 \mathrm{mg} / \mathrm{L} \mathrm{FeSO}$, $225 \mathrm{mg} / \mathrm{L}$

$\mathrm{CH}_{3} \mathrm{COONa}$, and $35 \mathrm{mg} / \mathrm{L}$ urea. Key physicochemical properties of the synthetic wastewater were determined every three days. In particular, the synthetic wastewater contained $111.3 \pm 13 \mathrm{mg} / \mathrm{L}$ total organic carbon (TOC), $6.4 \pm 0.9 \mathrm{mg} / \mathrm{L}$ total nitrogen (TN), $4.1 \pm 0.45 \mathrm{mg} / \mathrm{L}$ ammonium nitrogen $\left(\mathrm{NH}_{4}{ }^{+}\right)$, and $10.9 \pm 2.5 \mathrm{mg} / \mathrm{L}$ phosphate

$\left(\mathrm{PO}_{4}{ }^{3-}\right)$. The electrical conductivity and $\mathrm{pH}$ of this synthetic wastewater were $321 \pm 15$ $\mu \mathrm{S} / \mathrm{cm}$ and $6.2 \pm 0.3$, respectively.

A set of 30 TrOCs were selected to represent emerging chemicals of significant concern that ubiquitously present in municipal wastewater. A stock solution containing $25 \mu \mathrm{g} / \mathrm{mL}$ of each of TrOCs was prepared in pure methanol and stored at $-18^{\circ} \mathrm{C}$ in the dark. The stock solution was introduced daily to the synthetic wastewater to obtain a concentration of $5 \mu \mathrm{g} / \mathrm{L}$ of each compound.

\subsection{Biomimetic aquaporin FO membrane}

A flat-sheet aquaporin FO membrane obtained from Aquaporin Asia, Singapore was used in this study. The biomimetic FO membrane was fabricated via interfacial polymerization with embedded aquaporin proteins vesicles into a polyamide selective layer supported by a porous polysulfone supporting layer (Madsen et al., 2015).

Conventional CTA and TFC FO membranes obtained from Hydration Technology Innovation (Albany, OR) were also used in this study as benchmarks. The CTA membrane was fabricated via phase inversion and composed of a cellulose triacetate layer with an embedded woven supporting mesh. The TFC membrane was made by interfacial polymerization with a thin, selective polyamide active layer on the top of a 
porous polysulfone supporting layer (Cath et al., 2013).

\subsection{Osmotic membrane bioreactor}

A lab-scale, submerged OMBR system was used (Fig. 1). This system mainly comprised a glass bioreactor, a plate-and-frame FO membrane module, and a draw solution delivery and control unit. A peristaltic pump (Cole-Parmer, Vernon Hills, IL) controlled by a water level sensor was used to feed synthetic wastewater into the bioreactor. The membrane module was made of acrylic plastic and had a draw solution flow chamber with a length, width, and height of 150,80 , and $3 \mathrm{~mm}$, respectively. The FO membrane was sealed on the draw solution flow chamber with the active layer facing the mixed liquor and an effective area of $120 \mathrm{~cm}^{2}$. A gear pump (Micropump, Vancouver, WA) was used to circulate the draw solution to the membrane cell at a cross-flow rate of $0.75 \mathrm{~L} / \mathrm{min}$, corresponding to a cross-flow velocity of $5.2 \mathrm{~cm} / \mathrm{s}$.

\section{[Figure 1]}

The draw solution reseryoir was placed on a digital balance (Mettler-Toledo, Hightstown, USA) connected to a computer. An increase in the draw solution weight was recorded and used to determine the OMBR water flux. The draw solution concentration was maintained using a conductivity controller unit and a highly concentrated draw solution. A detailed description of the conductivity controller has been reported in our previous study (Luo et al., 2015). Briefly, the conductivity controller was consisted of a conductivity probe, a conductivity sensor, and a small peristaltic pump. The concentrated draw solution reservoir was also placed on the same digital balance with the working draw solution tank to avoid interference in water flux calculation.

\subsection{Operation of osmotic membrane bioreactor}

Activated sludge obtained from a conventional, lab-scale MBR was used to inoculate the OMBR system. The conventional MBR had been acclimatized to laboratory 
conditions and the synthetic wastewater for more than three months. Stable performance of the conventional MBR had achieved as indicated by its relatively constant and effective removal of total organic carbon (TOC) (>95\%). The initial mixed liquor suspended solid concentration (MLSS) of OMBR was adjusted to approximately $7 \mathrm{~g} / \mathrm{L}$. The bioreactor had an effective volume of $4 \mathrm{~L}$ and was continuously aerated to obtain a dissolved oxygen (DO) concentration of above 2 $\mathrm{mg} / \mathrm{L}$. The operating sludge retention time (SRT) was maintained at 20 days by daily withdrawing $200 \mathrm{~mL}$ mixed liquor. A $0.5 \mathrm{M} \mathrm{NaCl}$ solution was used as the draw solution whose concentration was maintained by the conductivity controller equipment and a $6 \mathrm{M} \mathrm{NaCl}$ solution. The working draw solution was replaced on a daily basis to avoid contaminant accumulation and overflow. The operating hydraulic retention time (HRT) was determined by the FO water flux and was in the range of 24 -36 hours, resulting in the system organic loading rate in the range of $74-109 \mathrm{~g}$ $\mathrm{TOC} /\left(\mathrm{m}^{3} \mathrm{~d}\right)$. The OMBR system was continuously operated for 20 days in a temperature-controlled room $\left(22 \pm 1^{\circ} \mathrm{C}\right)$. No membrane clean was conducted throughout the experiment.

\subsection{Analytical methods}

\subsubsection{Membrane transport parameters}

Membrane transport parameters were determined based on the standard methodology reported by Cath et al. (2013). Briefly, the water permeability coefficient (A) and salt $(\mathrm{NaCl})$ permeability coefficient $(B)$ was examined using a cross-flow RO system with deionized water and 2,000 $\mathrm{mg} / \mathrm{L} \mathrm{NaCl}$ solution as the feed solution, respectively. The RO water flux was recorded at an applied hydraulic pressure $(\Delta P)$ of 10 bar and a cross-flow velocity of $25 \mathrm{~cm} / \mathrm{s}$. Both feed and permeate samples were taken to determine the observed $\mathrm{NaCl}$ rejection $\left(R_{o b}\right)$. The $A$ and $B$ values were calculated as follows:

$$
A=\frac{J_{R O}}{\Delta P}
$$


$B=J_{N a C l}\left(\frac{1-R_{o b}}{R_{o b}}\right) \exp \left(-\frac{J_{N a C l}}{k_{f}}\right)$

where $J_{R O}$ and $J_{\mathrm{NaCl}}$ was the RO water flux $\left(\mathrm{L} / \mathrm{m}^{2} \mathrm{~h}\right)$ with deionized water and $\mathrm{NaCl}$ solution as the feed solution, respectively; $k_{f}$ was the mass transfer coefficient of the cross-flow RO membrane cell $(\mu \mathrm{m} / \mathrm{s})$, which was determined using the salt concentration at the membrane surface with the film theory for concentration polarization (Sutzkover et al., 2000):

$$
k_{f}=\frac{J_{\mathrm{NaCl}}}{\ln \left[\frac{\Delta P}{\pi_{b}-\pi_{p}}\left(1-\frac{J_{\mathrm{NaCl}}}{J_{R O}}\right)\right]}
$$

where $\pi_{p}$ and $\pi_{b}$ was the feed and permeate osmotic pressure (bar), respectively. They were determined by their salt concentrations according to the van't Hoff equation.

Membrane structural parameter $(S)$, which indicates the content of internal concentration polarization of the FO membrane, is defined as follows:

$$
S=\frac{l \tau}{\varepsilon}
$$

where $l$ is the supporting layer thickness, $\tau$ is the supporting layer tortuosity, and $\varepsilon$ is the supporting layer porosity.

Membrane $S$ value was experimentally determined using a cross-flow FO system with $0.5 \mathrm{M} \mathrm{NaCl}$ draw solution and deionized water feed in this study. Water flux $\left(J_{F O}\right)$ was recorded after stabilizing the system for two hours for $S$ value calculation based on the following equation:

$$
S=\frac{D_{s}}{J_{F O}} \ln \left(\frac{B+A \pi_{D, b}}{B+J_{F O}+A \pi_{F, m}}\right)
$$

where $D_{s}$ was the draw solute diffusivity $\left(\mathrm{m}^{2} / \mathrm{s}\right) ; \pi_{D, b}$ was the draw solution osmotic pressure (bar); and $\pi_{F, m}$ was the osmotic pressure at the membrane surface on the feed side (zero for deionized water feed). 


\subsubsection{Membrane surface charge, morphology, and hydrophobicity}

Membrane surface charge was measured by a SurPASS electrokinetic analyzer (Anton Paar $\mathrm{CmbH}$, Graz, Austria). Zeta potential of the membrane surface was calculated from the measured streaming potential using the Fairbrother-Maastin approach (Elimelech et al., 1994). All streaming potential measurements were performed in a background electrolyte solution (i.e. $10 \mathrm{mM} \mathrm{KCl}$ ). The background solution was also used to completely flush the cell before $\mathrm{pH}$ titration using either $0.5 \mathrm{M}$ hydrochloric acid or $0.5 \mathrm{M}$ potassium hydroxide.

A scanning electron microscopy (SEM) coupled with energy dispersive spectroscopy (EDS) (JCM-6000, JEOL, Tokyo, Japan) was used to characterize the membrane surface morphology and elementary composition. Prior to the SEM measurement, air-dried membrane samples were coated with an ultra-thin layer of gold using a sputter coater (SPI Module, West Chester, PA).

Membrane hydrophobicity was assessed by contact angle measurements using a Rame-Hart Goniometer (Model 250, Rame-Hart, Netcong, NJ) based on the standard sessile drop method. Ten water droplets were applied to each dried membrane sample. Contact angles on both sides of the droplet were recorded.

\subsubsection{Basic water quality parameters}

Total organic carbon (TOC) and total nitrogen (TN) were analyzed using a TOC/TN analyzer (TOC- $\mathrm{V}_{\mathrm{CSH}}$, Shimadzu, Kyoto). Ammonium $\left(\mathrm{NH}_{4}{ }^{+}\right)$and orthophosphate $\left(\mathrm{PO}_{4}{ }^{3-}\right)$ were measured by a flow injection analysis system (QuikChem 8500, Lachat, $\mathrm{CO})$. Removal of these contaminants by OMBR was determined based on the method described in the following section. An Orion 4-Star Plus pH/conductivity meter (Thermo Scientific, Waltham, MA) was used to measure the solution $\mathrm{pH}$ and electrical conductivity.

\subsubsection{Analysis of trace organic contaminants}

TrOC concentrations in wastewater, mixed liquor supernatant, and draw solution were 
analyzed every five days based on an analytic method reported by Hai et al. (2011). Briefly, this method involved solid phase extraction, derivatization, and quantification by a gas chromatography - mass spectrometry system (QP5000 GC-MS, Shimadzu, Kyoto).

Contaminant removal by OMBR was determined based on the method reported in our previous study (Luo et al., 2015). Briefly, a dilution factor (DF) was used to correct the draw solution dilution in calculating TrOC concentrations in the FO permeate:

$D F=\frac{V_{\text {Draw }}}{V_{F O}}$

where $V_{\text {Draw }}$ and $V_{F O}$ was the volume of the draw solution and water permeated through the FO membrane, respectively, when TrOC samples were collected for analysis.

TrOC removal by OMBR could be defined as follows:

$R_{\text {OMBR }}=\left(1-\frac{C_{\text {Draw }}}{C_{\text {Feed }}} D F\right) \times 100 \%$

where $C_{\text {Feed }}$ and $C_{\text {Draw }}$ was the measured TrOC concentration in the feed and draw solution, respectively.

TrOC removal by OMBR was the complementary result of biological degradation and aquaporin FO membrane rejection. Thus, biological removal of TrOCs $\left(R_{\text {Bio }}\right)$ was defined as:

$R_{\text {Bio }}=\left(1-\frac{C_{\text {Sup }} V_{\text {Bio }}+C_{\text {Draw }} D F \Delta V_{F O}}{C_{\text {Feed }} \Delta V}\right) \times 100 \%$

where $C_{\text {Sup }}$ was the TrOC concentration measured in the mixed liquor supernatant; $V_{B i o}$ was the effective bioreactor volume; and $\Delta V_{F O}$ was the volume of water permeated through the FO membrane between time $t$ and $t-\Delta t$, which was equal to the volume of wastewater fed into the bioreactor $(\Delta V)$. 
Based on eqs. (7) and (8), the observed rejection of TrOCs by the aquaporin FO membrane $\left(R_{O b F O}\right)$ was defined as follows:

$R_{O b F O}=R_{O M B R}-R_{\text {Bio }}$

It is noteworthy that the observed rejection rate could not show the real rejection capacity of the aquaporin FO membrane, but quantify its contribution toward TrOC removal in OMBR.

\section{Results and discussion}

\subsection{Key properties of the aquaporin FO membrane}

Key properties of the aquaporin FO membrane were evaluated and compared to CTA and TFC FO membranes currently available in the market. Water permeability coefficient ( $A$ value) of the aquaporin membrane was significantly higher than that of the CTA membrane, but was comparable or only slightly lower than that of the TFC membrane (Table 1). This observation could be attributed to the difference in their membrane structural parameter ( $S$ value) (Table 1), which indicates the extent of the internal concentration polarization in the FO process (McCutcheon \& Elimelech, 2006). As a result, the aquaporin and TFC membranes exhibited high and comparable water flux of approximately 15.6 and $15 \mathrm{~L} / \mathrm{m}^{2} \mathrm{~h}$, respectively, in the cross-flow FO experiment with $0.5 \mathrm{NaCl}$ draw solution and deionized water feed solution. On the other hand, the CTA membrane showed a much lower water flux of $5.5 \mathrm{~L} / \mathrm{m}^{2} \mathrm{~h}$ under the same testing condition.

\section{[Table 1]}

By incorporating highly selective aquaporin vesicles into membrane active layer, the aquaporin $\mathrm{FO}$ membrane showed much lower salt $(\mathrm{NaCl})$ permeability ( $B$ value) than both CTA and TFC membranes (Table 1). Thus, the reverse salt $(\mathrm{NaCl})$ flux of the aquaporin membrane was $0.085 \mathrm{mmol} / \mathrm{hm}^{2}$, which was considerably lower than that of the CTA $\left(82.7 \mathrm{mmol} / \mathrm{hm}^{2}\right)$ and TFC $\left(5.5 \mathrm{mmol} / \mathrm{hm}^{2}\right)$ membranes, in the cross-flow 
FO experiment with $0.5 \mathrm{NaCl}$ draw and deionized water feed. Moreover, the aquaporin $\mathrm{FO}$ membrane also demonstrated an excellent capacity for salt $(\mathrm{NaCl})$ rejection (Table 1). Compared to the CTA and TFC membranes, the aquaporin FO membrane was more negatively charged and hydrophobic (Table 1), possibly due to the physical features of lipid vesicles immobilized into the membrane selective layer (Xie et al., 2013).

\subsection{Performance of the aquaporin FO membrane in OMBR operation}

\subsubsection{Salinity build-up and water production}

Salinity build-up in the bioreactor is an inherent issue associated with OMBR operation, due to the high salt rejection from wastewater by the FO membrane, and more importantly, the reverse draw solute diffusion (Lay et al., 2010). As discussed above, the reverse salt flux through the aquaporin FO membrane was insignificant (Table 1). Thus, the observed salinity increase in the bioreactor from approximately 0.4 to $8.6 \mathrm{mS} / \mathrm{cm}$ within 20 days of OMBR operation (Fig. 2) can be attributed mostly to the build-up of salts originally from the influent. Indeed, this salinity increase was less severe when comparing to previous OMBR studies using conventional CTA and TFC FO membranes under similar operating conditions. For example, Luo et al. (2017) observed an increase in the mixed liquor conductivity from 0.3 to nearly 11 $\mathrm{mS} / \mathrm{cm}$ within 20 days during OMBR operation with the conventional TFC FO membrane.

\section{[Figure 2]}

Water flux of the aquaporin FO membrane decreased continuously during OMBR operation (Fig. 2). This observation is consistent with that reported previously and could be attributed to salinity build-up in the bioreactor and membrane fouling (Xiao et al., 2011; Wang et al., 2016). Salinity build-up in the bioreactor could increase the osmotic pressure in the mixed liquor side and thus reduce the net driving force (i.e. effective trans-membrane osmotic pressure) for water permeation (Xiao et al., 2011). 
With osmotic pressure as the driving force, FO has relatively low fouling propensity and high fouling reversibility in wastewater treatment (Mi \& Elimelech, 2010). Moreover, in this study, routine approach was used in OMBR operation where continuous aeration required for sludge growth and metabolism could produce air bubbles to alleviate the formation and attachment of cake layer on the membrane surface. However, a patchy and thin fouling layer, mainly consisted of carbon, nitrogen, oxygen, and sulfur, was observed on the aquaporin membrane surface at the conclusion of OMBR operation. More significant fouling was formed in the upper region of the membrane, where air bubbling was weakened by passing through the mixed liquor (Braak et al., 2011).

\subsubsection{Removal of bulk organic matter and nutrients}

By coupling biological treatment with highly selective aquaporin FO membrane, OMBR could effectively remove organic matter and nutrients (Fig. 3). Despite salinity build-up in the bioreactor (Fig. 2), biological treatment was stable during OMBR operation, as indicated by negligible $\mathrm{TOC}$ and $\mathrm{NH}_{4}{ }^{+}$concentrations in the mixed liquor (Fig. 3A\&B). Moreover, the MLSS concentration and the specific oxygen uptake rate of activated sludge were relatively constant in OMBR operation, corroborating stable biomass growth and activity. Indeed, most microorganisms in activated sludge are non-halophilic and able to tolerate salinity up to $10 \mathrm{~g} / \mathrm{L} \mathrm{NaCl}$ without acclimatization (Woolard \& Irvine, 1995; Lay et al., 2010). Nevertheless, salinity build-up in the bioreactor needs to be controlled to circumvent adverse effects on biological treatment for sustainable OMBR operation, since higher saline conditions $(>10 \mathrm{~g} / \mathrm{L} \mathrm{NaCl})$ can result in cell dehydration, and eventually, the plasmolysis and inactivity of microorganisms in activated sludge (Lay et al., 2010).

\section{[Figure 3]}

Without denitrification under aerobic condition, TN removal by activated sludge is commonly ineffective and only dependent on microbial assimilation (Gerrity et al., 
2013). Thus, in this study, only $60-80 \%$ TN was removed by OMBR (Fig. 3C), which could be attributed mainly to the rejection of nitrogen species by the aquaporin FO membrane. Indeed, although there were several fluctuations, TN concentration increased in the mixed liquor. Nevertheless, a decrease in TN removal was observed at the end of OMBR operation, indicating that the aquaporin FO membrane had a moderate capacity for the rejection of nitrogen species, especially nitrate that could be converted from $\mathrm{NH}_{4}{ }^{+}$by complete nitrification under aerobic condition. Similar results were also reported in previous OMBR studies with conventional CTA and TFC FO membranes (Zhang et al., 2017).

Phosphorus removal in biological treatment also depends on microbial assimilation, especially by phosphate accumulating microorganisms (PAOs) (Seviour et al., 2003). However, the activity and metabolism of PAOs could be easily inhibited in saline environment (Panswad \& Anan, 1999). It has been reported that increased salinity in sequencing batch reactor (Uygur \& Karg, 2004) and conventional MBR (Luo et al., 2016b) led to a dramatic and continuous decrease in phosphorus removal.

Nevertheless, given their relatively large hydrated radius and negative charge, $\mathrm{PO}_{4}{ }^{3-}$ ions were effectively rejected by the aquaporin FO membrane and thus accumulated considerably in the mixed liquor, with negligible permeation into the draw solution (Fig. 3D).

\subsubsection{Removal of trace organic contaminants}

All 30 TrOCs investigated in this study could be effectively removed ( $>85 \%)$ by OMBR (Fig. 4), due to the complementarity of biological treatment and highly selective aquaporin FO membrane. As shown in Fig. 4, biological treatment played the dominating role for the removal of most TrOCs, with a few exceptions, such as clofibric acid, carbamazepine, and atrazine. This removal deviation could be attributed to the different properties of these TrOCs, such as hydrophobicity and molecular feature. Based on a predictive protocol reported by Tadkaew et al. (2011), the effective octanol - water partition coefficient (i.e. $\log D$ ) at the mixed liquor $\mathrm{pH}$ 
of 8 was used to classify the 30 TrOCs as hydrophilic $(\log D<3.2)$ and hydrophobic $(\log D>3.2)$.

\section{[Figure 4]}

All hydrophobic TrOCs ( $\log D>3.2)$ could be effectively removed by activated sludge, with removal rates higher than $90 \%$ (Fig. 4). Due to their hydrophobic interactions with sludge, for example, via their aliphatic and aromatic functional groups with the lipid fraction of sludge, hydrophobic TrOCs could easily absorb onto activated sludge for further biodegradation (Besha et al., 2017). As a result, the contribution of the aquaporin FO membrane to the overall removal of hydrophobic TrOCs in OMBR was insignificant (less than 5\%).

Removal of hydrophilic TrOCs $(\log D<3.2)$ via biological treatment varied considerably (Fig. 4), depending on their intrinsic biodegradability. Some compounds were removed by more than $80 \%$ in the bioreactor. These TrOCs include salicylic acid, ketoprofen, naproxen, metronidazole, ibuprofen, gemfibrozil, pentachlorophenol, DEET, and ametryn. On the other hand, poor removals were observed for several other TrOCs, including clofibric acid, fenoprop, primidone, carbamazepine, and atrazine, with removal rates less than $30 \%$. This removal difference was in good agreement with that reported previously in conventional MBR studies (Kimura et al., 2005; Besha et al., 2017), and could be further attributed to different functional groups in the molecular structure of these hydrophilic compounds. In general, hydrophilic TrOCs containing strong electron-donating functional groups (e.g. amine and hydroxyl) could be effectively biodegraded, due to their preferential to initial electrophilic attack by oxygenase of aerobic bacteria; while compounds with electron-withdrawing functional groups (e.g. chloro, amide, and nitro) were recalcitrant to biodegradation, because these functional groups could generate electron deficiency and thus constrain the oxidative catabolism of compounds (Knackmuss, 1996; Tadkaew et al., 2011). 
The aquaporin FO membrane complemented well biological treatment to ensure effective TrOC removal by OMBR, with significant contribution toward the removal of hydrophilic and biologically persistent compounds (Fig. 4). This result was consistent with that reported in previous OMBR studies, where the role of conventional CTA and TFC FO membranes for TrOC removal was investigated (Luo et al., 2017; Zhang et al., 2017). Although there is no direct comparison, the aquaporin FO membrane should be able to make more contribution than these two conventional FO membranes to increase the removal of hydrophilic and biologically recalcitrant TrOCs in OMBR given its higher solute rejection capacity (Table 1). Indeed, Zhang et al. (2017) demonstrated that the highly selective TFC FO membrane could enhance the removal hydrophilic and biologically persistent TrOCs by OMBR in comparison with the CTA FO membrane. It is noteworthy that the stable and high removal of TrOCs observed in this study also suggested the robustness and stability of the aquaporin FO membrane when integrated with activated sludge treatment.

\section{Implications}

Proteoliposomes (i.e. lipid vesicles with aquaporin proteins) are typically incorporated into the dense polymeric matrix to strengthen biomimetic aquaporin membranes (Zhao et al., 2012; Giwa et al., 2017). The aquaporin FO membrane used in this study was fabricated via interfacial polymerization with proteoliposomes embedded into a polyamide selective layer supported by a porous polysulfone supporting layer (Madsen et al., 2015). Indeed, the SEM micrograph of the aquaporin FO membrane showed that round-shape nodules, possibly aquaporin proteins vesicles, were covered by the leaf-like polyamide structure. Further analysis of the membrane cross-section by the transmission electron microscopy also demonstrated the embedment of round-shape nodules within the membrane interface. Thus, the polyamide selective layer could prevent proteoliposomes from biological degradation, endowing the aquaporin FO membrane with an uncompromised performance in OMBR operation (indicated by the stable and high contaminant removal). A stable performance of 
biomimetic aquaporin membranes was also demonstrated in long-term RO desalination (over 100 days) with periodical membrane cleaning by chemical agents (Qi et al., 2016). Although long-term studies are necessary to valid the stability of biomimetic aquaporin membranes against biological damage, this study shed light on their promising potential in OMBR applications.

\section{Conclusion}

Results reported here demonstrate the potential of biomimetic aquaporin membranes for OMBR application. Compared to conventional CTA and TFC FO membranes, the aquaporin FO membrane exhibited much better transport properties, particularly smaller reverse salt flux without compromising water permeation, which thereby resulted in less severe salinity build-up in the bioreactor during OMBR operation. Moreover, the aquaporin FO membrane could complement well biological treatment for excellent contaminant removal in OMBR, with notable contribution towards the removal of biologically persistent TrOCs. Stable contaminant removal over OMBR operation also suggests the compatibility of the aquaporin FO membrane with activated sludge treatment.

\section{Acknowledgements}

This research was supported under the Australian Research Council's Discovery Project funding scheme (Project DP140103864) and National Natural Science Foundation of China (Project 51708547). Dr. Jinguo Kang is gratefully acknowledged for his assistance with the analysis of trace organic contaminants.

\section{Acknowledgements}

Supplementary data of this study can be found in the e-version of this paper online.

\section{References}

1. Achilli, A., Cath, T.Y., Marchand, E.A., Childress, A.E. 2009. The forward osmosis membrane bioreactor: A low fouling alternative to MBR processes. 
Desalination, 239(1), 10-21.

2. Aftab, B., Khan, S.J., Maqbool, T., Hankins, N.P. 2017. Heavy metals removal by osmotic membrane bioreactor (OMBR) and their effect on sludge properties. Desalination, 403, 117-127.

3. Alturki, A.A., McDonald, J., Khan, S.J., Hai, F.I., Price, W.E., Nghiem, L.D. 2012. Performance of a novel osmotic membrane bioreactor (OMBR) system: Flux stability and removal of trace organics. Bioresour. Technol., 113, 201-206.

4. Besha, A.T., Gebreyohannes, A.Y., Tufa, R.A., Bekele, D.N., Curcio, E., Giorno, L. 2017. Removal of emerging micropollutants by activated sludge process and membrane bioreactors and the effects of micropollutants on membrane fouling: A review. J. Environ. Chem. Eng., 5(3), 2395-2414.

5. Bowden, K.S., Achilli, A., Childress, A.E. 2012. Organic ionic salt draw solutions for osmotic membrane bioreactors. Bioresour. Technol., 122, 207-216.

6. Braak, E., Alliet, M., Schetrite, S., Albasi, C. 2011. Aeration and hydrodynamics in submerged membrane bioreactors. J. Membr. Sci., 379(1-2), 1-18.

7. Cath, T.Y., Hancock, N.T., Lampi, J., Nghiem, L.D., Xie, M., Yip, N.Y., Elimelech, M., McCutcheon, J.R., McGinnis, R.L., Achilli, A., Anastasio, D., Brady, A.R., Childress, A.E., Farr, I.V. 2013. Standard methodology for evaluating membrane performance in osmotically driven membrane processes. Desalination, 312, 31-38.

8. Cornelissen, E.R., Harmsen, D., Beerendonk, E.F., Qin, J.J., Oo, H., De Korte, K.F., Kappelhof, J.W.M.N. 2011. The innovative osmotic membrane bioreactor (OMBR) for reuse of wastewater. Water Sci. Technol., 63(8), 1557-1565.

9. Elimelech, M. 2006. The global challenge for adequate and safe water. J. Water Supply: Res. Technol. AQUA, 55(1), 3-10.

10. Elimelech, M., Chen, W.H., Waypa, J.J. 1994. Measuring the zeta (electrokinetic) potential of reverse osmosis membranes by a streaming potential analyzer. Desalination, 95(3), 269-286. 
11. Fane, A.G., Wang, R., Hu, M.X. 2015. Synthetic Membranes for Water Purification: Status and Future. Angew. Chem. Int. Ed., 54, 3368-3386.

12. Gerrity, D., Pecson, B., Trussell, R.S., Trussell, R.R. 2013. Potable reuse treatment trains throughout the world. J. Water Supply: Res. Technol. AQUA, 62(6), 321-338.

13. Giwa, A., Hasan, S.W., Yousuf, A., Chakraborty, S., Johnson, D.J., Hilal, N. 2017. Biomimetic membranes: A critical review of recent progress. Desalination, 420, 403-424.

14. Hai, F.I., Tessmer, K., Nguyen, L.N., Kang, J., Price, W.E., Nghiem, L.D. 2011. Removal of micropollutants by membrane bioreactor under temperature variation. J. Membr. Sci., 383(1), 144-151.

15. Holloway, R.W., Regnery, J., Nghiem, L.D., Cath, T.Y. 2014. Removal of trace organic chemicals and performance of a novel hybrid ultrafiltration-osmotic membrane bioreactor. Environ. Sci. Technol., 48(18), 10859-10868.

16. Holloway, R.W., Wait, A.S., Da Silva, A.F., Herron, J., Schutter, M.D., Lampi, K., Cath, T.Y. 2015. Long-term pilot scale investigation of novel hybrid ultrafiltration-osmotic membrane bioreactors. Desalination, 363, 64-74.

17. Huang, L., Lee, D.J. 2015. Membrane bioreactor: A mini review on recent R\&D works. Bioresour. Technol., 194, 383-388.

18. Jensen, M.O., Mouritsen, O.G. 2006. Single-channel water permeabilities of Escherichia coli aquaporins AqpZ and GlpF. Biophys. J., 90(7), 2270-2284.

19. Kimura, K., Hara, H., Watanabe, Y. 2005. Removal of pharmaceutical compounds by submerged membrane bioreactors (MBRs). Desalination, 178(1), 135-140.

20. Knackmuss, H.J. 1996. Basic knowledge and perspectives of bioelimination of xenobiotic compounds. J. Biotechnol., 513, 287-295.

21. Lay, W.C.L., Liu, Y., Fane, A.G. 2010. Impacts of salinity on the performance of high retention membrane bioreactors for water reclamation: A review. Water Res., 44(1), 21-40. 
22. Li, D., Yan, Y., Wang, H. 2016. Recent advances in polymer and polymer composite membranes for reverse and forward osmosis processes. Prog. Polym. Sci., 61, 104-155.

23. Li, X., Chou, S., Wang, R., Shi, L., Fang, W., Chaitra, G., Tang, C.Y., Torres, J., Hu, X., Fane, A.G. 2015. Nature gives the best solution for desalination: Aquaporin-based hollow fiber composite membrane with superior performance. J. Membr. Sci., 494, 68-77.

24. Li, X., Loh, C.H., Wang, R., Widjajanti, W., Torres, J. 2017. Fabrication of a robust high-performance FO membrane by optimizing substrate structure and incorporating aquaporin into selective layer. J. Membr. Sci., 525, 257-268.

25. Luo, W., Hai, F.I., Price, W.E., Elimelech, M., Nghiem, L.D. 2016a. Evaluating ionic organic draw solutes in osmotic membrane bioreactors for water reuse. J. Membr. Sci., 514, 636-645.

26. Luo, W., Hai, F.I., Price, W.E., Nghiem, L.D. 2015. Water extraction from mixed liquor of an aerobic bioreactor by forward osmosis: Membrane fouling and biomass characteristics assessment. Sep. Purif. Technol., 145(0), 56-62.

27. Luo, W., Phan, H.V., Hai, F.I., Price, W.E., Guo, W., Ngo, H.H., Yamamoto, K., Nghiem, L.D. 2016b. Effects of salinity build-up on the performance and bacterial community structure of a membrane bioreactor. Bioresour. Technol., 200, 305-310.

28. Luo, W., Phan, H.V., Xie, M., Hai, F.I., Price, W.E., Elimelech, M., Nghiem, L.D. 2017. Osmotic versus conventional membrane bioreactors integrated with reverse osmosis for water reuse: Biological stability, membrane fouling, and contaminant removal. Water Res., 109, 122-134.

29. Madsen, H.T., Bajraktari, N., Hélix-Nielsen, C., Van der Bruggen, B., Søgaard, E.G. 2015. Use of biomimetic forward osmosis membrane for trace organics removal. J. Membr. Sci., 476, 469-474.

30. McCutcheon, J.R., Elimelech, M. 2006. Influence of concentrative and dilutive 
internal concentration polarization on flux behavior in forward osmosis. J. Membr. Sci., 284(1-2), 237-247.

31. Mi, B., Elimelech, M. 2010. Organic fouling of forward osmosis membranes: Fouling reversibility and cleaning without chemical reagents. J. Membr. Sci., 348(1), 337-345.

32. Nguyen, N.C., Nguyen, H.T., Chen, S.S., Ngo, H.H., Guo, W., Chan, W.H., Ray, S.S., Li, C.W., Hsu, H.T. 2016. A novel osmosis membrane bioreactor-membrane distillation hybrid system for wastewater treatment and reuse. Bioresour. Technol., $209,8-15$

33. Panswad, T., Anan, C. 1999. Impact of high chloride wastewater on an anaerobic anoxic aerobic process with and without inoculation of chloride acclimated seeds. Water Res., 33(5), 1165-1172.

34. Qi, S., Wang, R., Chaitra, G.K.M., Torres, J., Hu, X., Fane, A.G. 2016. Aquaporin-based biomimetic reverse osmosis membranes: Stability and long term performance. J. Membr. Sci., 508, 94-103.

35. Seviour, R.J., Mino, T., Onuki, M. 2003. The microbiology of biological phosphorus removal in activated sludge systems. FEMS Microbiol. Rev., 27(1), 99-127.

36. Shannon, M.A., Bohn, P.W., Elimelech, M. 2008. Science and technology for water purification in the coming decades. Nature, 452, 301-310.

37. Sutzkover, I., Hasson, D., Semiat, R. 2000. Simple technique for measuring the concentration polarization level in a reverse osmosis system. Desalination, 131(1), 117-127.

38. Tadkaew, N., Hai, F.I., McDonald, J.A., Khan, S.J., Nghiem, L.D. 2011. Removal of trace organics by MBR treatment: The role of molecular properties. Water Res., 45(8), 2439-2451.

39. Tang, C., Wang, Z., Petrinić, I., Fane, A.G., Hélix-Nielsen, C. 2015. Biomimetic aquaporin membranes coming of age. Desalination, 368, 89-105. 
40. Uygur, A., Karg, F. 2004. Salt inhibition on biological nutrient removal from saline wastewater in a sequencing batch reactor. Enzyme Microb. Technol., 34, $313-318$.

41. van Loosdrecht, M.C.M., Brdjanovic, D. 2014. Anticipating the next century of wastewater treatment. Science, 344(6191), 1452-1453.

42. Wang, X., Chen, Y., Yuan, B., Li, X.F., Ren, Y.P. 2014a. Impacts of sludge retention time on sludge characteristics and membrane fouling in a submerged osmotic membrane bioreactor. Bioresour. Technol., 161, 340-347.

43. Wang, X., Yuan, B., Chen, Y., Li, X.F., Ren, Y.P. 2014b. Integration of micro-filtration into osmotic membrane bioreactors to prevent salinity build-up. Bioresour. Technol., 167, 116-123.

44. Wang, X., Zhao, Y., Yuan, B., Wang, Z., Li, X., Ren, Y. 2016. Comparison of biofouling mechanisms between cellulose triacetate (CTA) and thin-film composite (TFC) polyamide forward osmosis membranes in osmotic membrane bioreactors. Bioresour. Technol,, 202, 50-58.

45. Werber, J.R., Osuji, C.O., Elimelech, M. 2016. Materials for next-generation desalination and water purification membranes. Nat. Mater. , 1(5), 16018-16033.

46. Woolard, C.R., Irvine, R.L. 1995. Treatment of hypersaline wastewater in the sequencing batch reactor. Water Res., 29(4), 1159-1168.

47. Xiao, D., Tang, C.Y., Zhang, J., Lay, W.C.L., Wang, R., Fane, A.G. 2011. Modeling salt accumulation in osmotic membrane bioreactors: Implications for FO membrane selection and system operation. J. Membr. Sci., 366(1-2), 314-324.

48. Xie, W., He, F., Wang, B., Chung, T.-S., Jeyaseelan, K., Armugam, A., Tong, Y.W. 2013. An aquaporin-based vesicle-embedded polymeric membrane for low energy water filtration. J. Mater. Chem. A, 1(26), 7592-7600.

49. Zhang, B., Song, X., Nghiem, L.D., Li, G., Luo, W. 2017. Osmotic membrane bioreactors for wastewater reuse: Performance comparison between cellulose triacetate and polyamide thin film composite membranes. J. Membr. Sci., 539, 
383-391.

50. Zhao, Y., Qiu, C., Li, X., Vararattanavech, A., Shen, W., Torres, J., Hélix-Nielsen, C., Wang, R., Hu, X., Fane, A.G., Tang, C.Y. 2012. Synthesis of robust and high-performance aquaporin-based biomimetic membranes by interfacial polymerization-membrane preparation and $\mathrm{RO}$ performance characterization. $\mathrm{J}$. Membr. Sci., 423-424, 422-428.

\section{LIST OF TABLES}

Table 1: Key properties of the aquaporin and two conventional FO membranes (average \pm standard deviation of triplicate measurements)

\begin{tabular}{llll}
\hline Parameters & Aquaporin & CTA & TFC \\
\hline Pure water permeability & $2.09 \pm 0.02$ & $0.84 \pm 0.03$ & $2.50 \pm 0.25$ \\
$\left(\mathrm{~L} / \mathrm{m}^{2} \mathrm{~h}\right.$-bar $)$ & & & \\
Salt $(\mathrm{NaCl})$ permeability & $0.07 \pm 0.01$ & $0.32 \pm 0.06$ & $0.19 \pm 0.03$ \\
$\left(\mathrm{~L} / \mathrm{m}^{2} \mathrm{~h}\right)$ & & & \\
Membrane structural parameter & $301 \pm 36$ & $575 \pm 28$ & $245 \pm 35$ \\
$(\mu \mathrm{m})$ & & & \\
Observed NaCl rejection & & & \\
$(\%)$ & $99.9 \pm 0.1$ & $92.0 \pm 1.4$ & $98.0 \pm 0.2$ \\
Contact angle & & & \\
$\left({ }^{\circ}\right)$ & $74.5 \pm 8.9$ & $60.4 \pm 5.2$ & $42.3 \pm 3.2$ \\
Zeta potential at $\mathrm{pH} 8$ & & & \\
$(\mathrm{mV})$ & $-16.4 \pm 2.3$ & $-4.5 \pm 0.4$ & $-14.2 \pm 0.5$ \\
\hline
\end{tabular}

\section{LIST OF FIGURES}




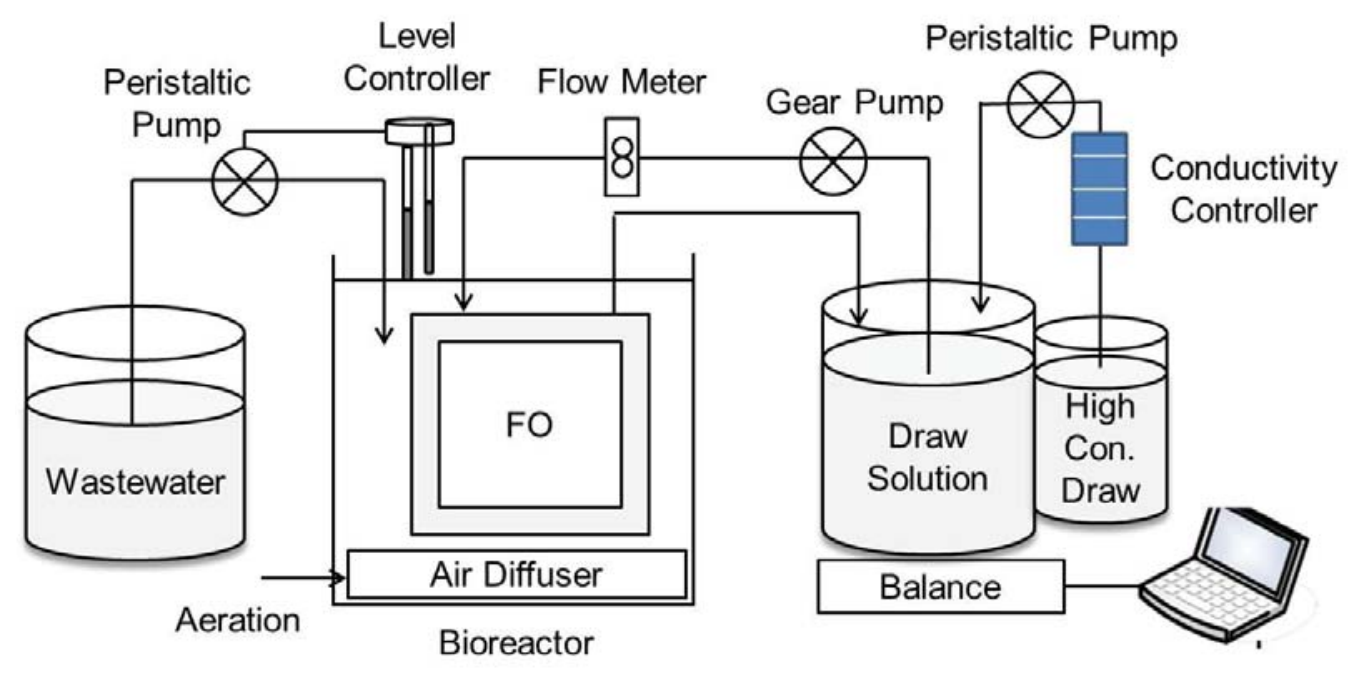

Fig. 1: Schematic diagram of the osmotic membrane bioreactor system.

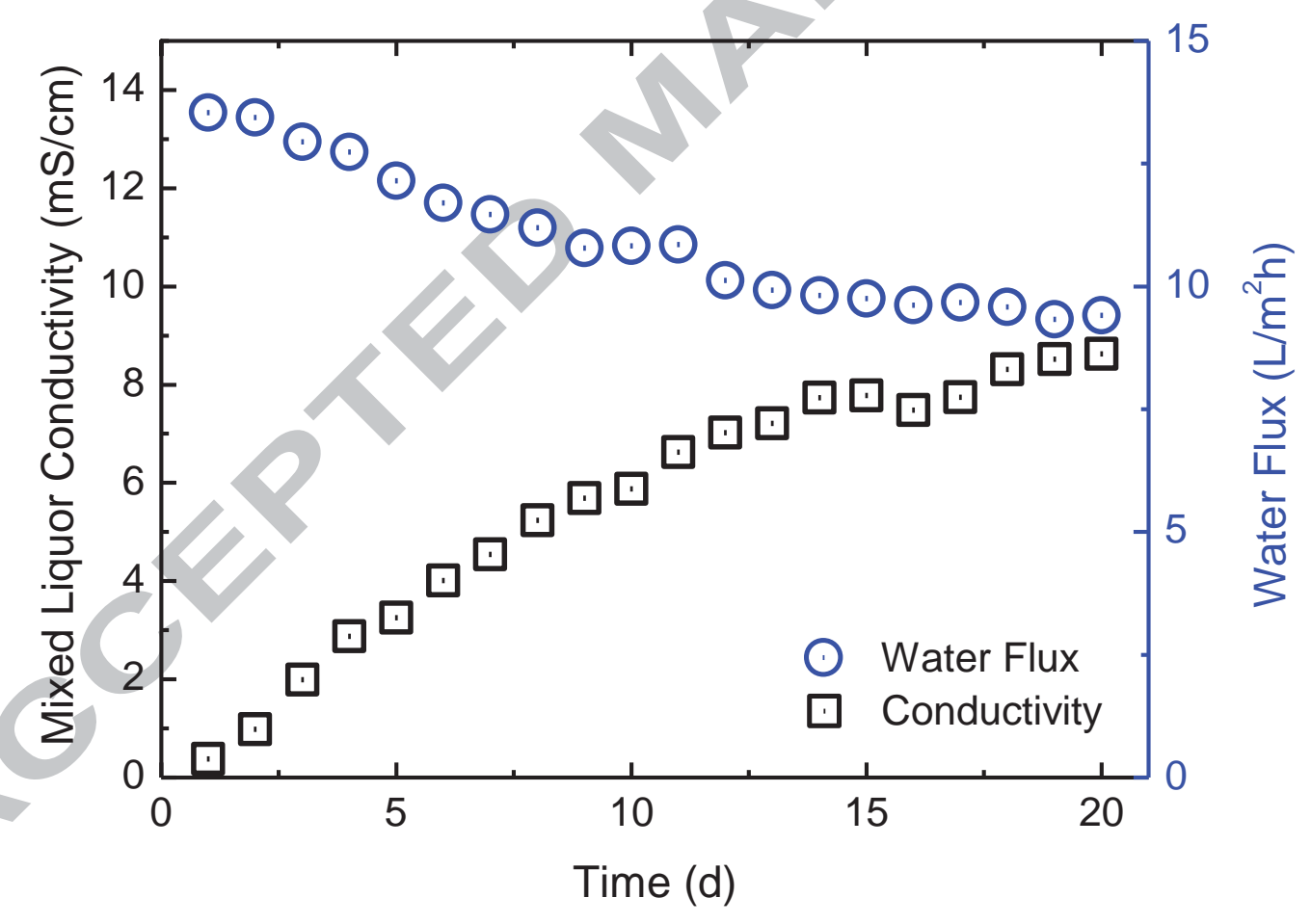

Fig. 2: Mixed liquor conductivity and water flux during OMBR operation using the aquaporin FO membrane. Experimental conditions: draw solution $=0.5 \mathrm{M} \mathrm{NaCl}$; cross-flow velocity $=5.2 \mathrm{~cm} / \mathrm{s} ; \mathrm{DO}=2 \mathrm{mg} / \mathrm{L} ;$ initial MLSS $=6.8 \mathrm{~g} / \mathrm{L} ; \mathrm{SRT}=20 \mathrm{~d}$; HRT $=24-36 \mathrm{~h}$; temperature $=22 \pm 1{ }^{\circ} \mathrm{C}$. 


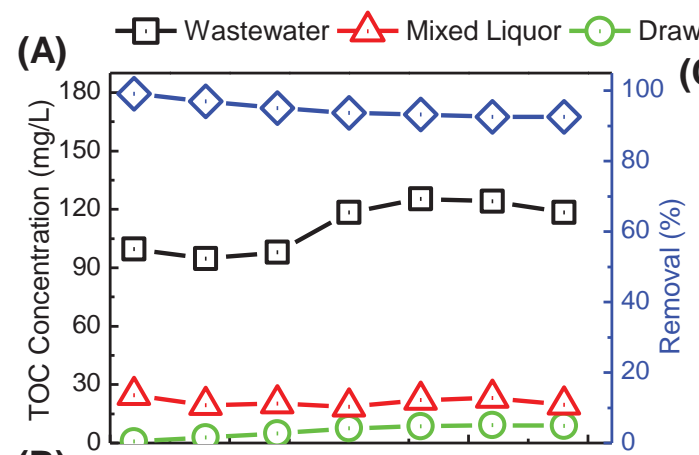

(B)

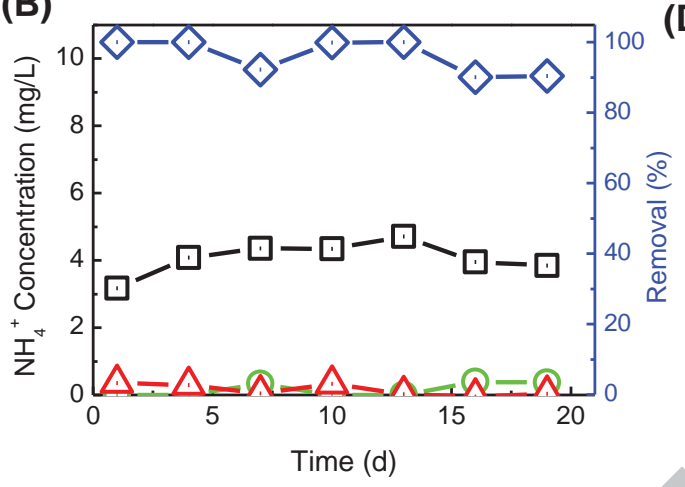

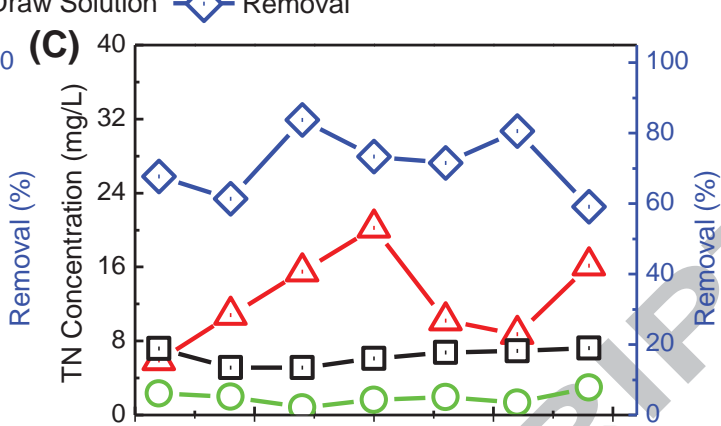

(D)

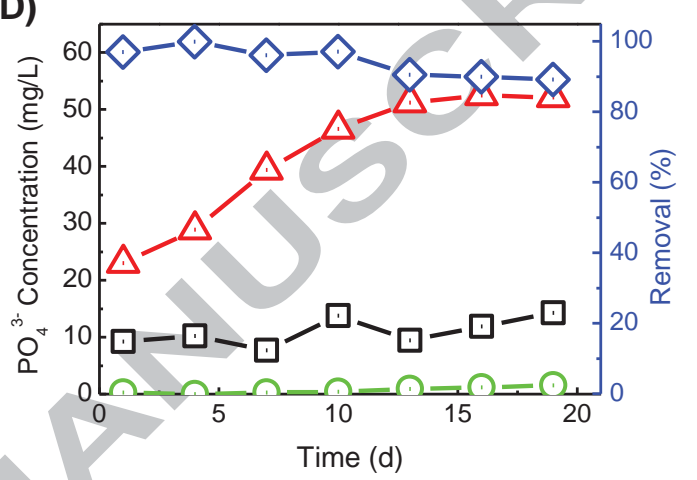

Fig. 3: (A) TOC, (B) TN, (C) $\mathrm{NH}_{4}{ }^{+}$, and (D) $\mathrm{PO}_{4}{ }^{3-}$ concentrations as well as their overall removal in OMBR using the aquaporin FO membrane. Experimental conditions are as described in Fig. 2. 


\section{ACCEPTED MANUSCRIPT}

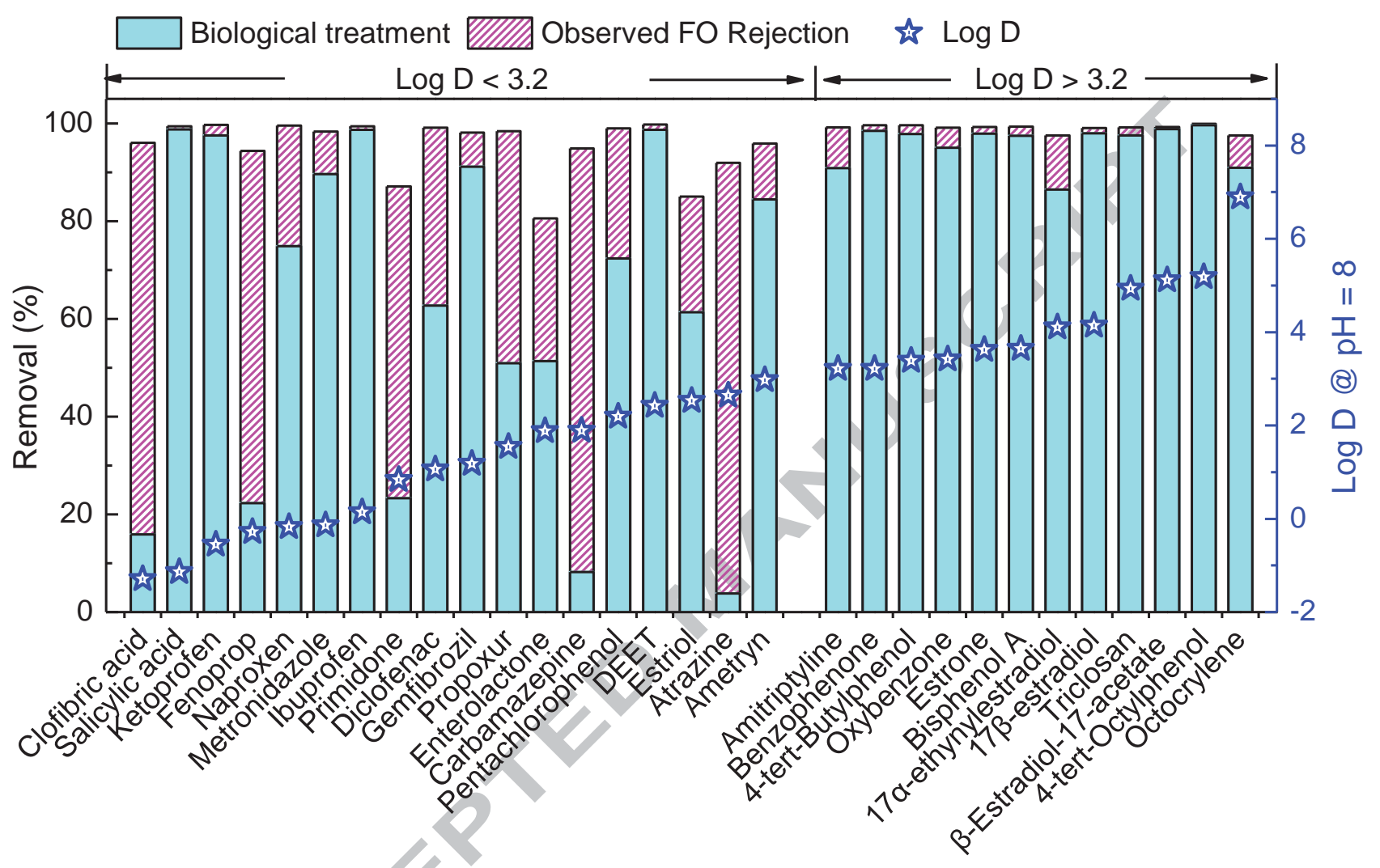


Fig. 4: Removal of TrOCs by the biological treatment and the FO rejection during OMBR operation using the aquaporin membrane. Average removal data obtained from four measurements (once every 5 days) are shown, with the standard deviation in the range of 0.1 to $30 \%$. TrOCs are ordered according to their effective octanol water partition coefficient (i.e. $\log D$ ) at solution $\mathrm{pH}$ of 8 . The observed FO rejection shows the removal difference between the bioreactor and OMBR. Experimental conditions are as described in Fig. 2. 


\section{Highlights}

- Aquaporin FO membrane showed better transport properties than conventional membranes

- Aquaporin FO membrane resulted in less salinity build-up in OMBR operation

- Aquaporin FO membrane exhibited stable performance in OMBR operation

- Excellent contaminant removal by OMBR was achieved with the aquaporin membrane 